Global Health Centre, Graduate Institute of International and Development Studies, Geneva, Switzerland

Correspondence to: S Moon suerie.moon@graduateinstitute.ch Cite this as: BMJ 2021;374:n2256 http://dx.doi.org/10.1136/bmj.n2256 Published: 20 September 2021

\title{
Embedding global access in development of future pandemic vaccines
}

\author{
Public investment in vaccines must be governed by global rules on knowledge sharing \\ Suerie Moon, Surabhi Agarwal, Anna Becker, Adrian Alonso Ruiz
}

Faster, broader, fairer global access to covid-19 vaccines is needed now. Vaccines can protect lives and livelihoods, help end the pandemic, mitigate threats of increased impoverishment and inequality, and reduce the risk of new variants. ${ }^{1}$ It makes ethical, epidemiological, and economic sense to redistribute doses from high income countries, which have more than they can use and a disproportionate share of global supply, to low and middle income countries facing severe shortages. ${ }^{2}$ So does proactively transferring vaccine technology to help scale-up production in all regions so that no country has to go without. ${ }^{3}$

The development of the first covid-19 vaccines in record time was a scientific success but a "catastrophic moral failure." ${ }^{4}$ As of 1 September, high and upper middle income countries had vaccinated over $60 \%$ of their populations with at least one dose, while lower middle income countries had reached just $24 \%$ and low income countries less than $2 \% .5$ Covax, the multilateral initiative for vaccine access, has purchased doses covering only $16.6 \%$ of participating countries' populations. International donations can help but are insufficient and unreliable: only about $10 \%$ of the nearly 15 billion doses secured globally have been earmarked for donation. ${ }^{6}$

Covid-19 vaccines were developed with at least $\$ 5.6 \mathrm{bn}$ (€4bn; €5bn) in upfront public investments and a further \$45b in public advance purchase commitments (reducing risk to manufacturers), building on over $\$ 17 \mathrm{bn}$ in public funding for basic research. ${ }^{7}$ But governments did not leverage this funding to ensure global access. Avoiding repetition of this catastrophe with the next generation of covid-19 vaccines-and in future pandemics-will require new international agreements and financing.

Although the currently available covid-19 vaccines are demonstrably safe and effective, we still need vaccines that are easier to use (heat stable, single dose, needle free), more effective at blocking infection, affordable, and accessible to all. Nearly 300 further candidates are under development, including 69 in late stage clinical trials (phase II or III), ${ }^{9}$ offering an important opportunity to do better in this pandemic, and the next.

\section{Conditional funding}

Making the next generation of covid-19 vaccines accessible requires that clear conditions are built into future public and philanthropic investments. Funding made conditional on data sharing would facilitate faster vaccine development, while compulsory sharing of technology, know-how, and other intellectual property would help scale-up production of successful candidates. Finally, requiring producers to price vaccines at fair, affordable levels, and to supply countries on the basis of need rather than wealth would expand access.

However, the current market based approach handsomely rewards the opposite-the hoarding of data, know-how, and intellectual property and selling vaccines to the highest bidder. The 2021 global market for covid-19 vaccines is estimated at up to $\$ 190 \mathrm{obn}^{10}$ with Pfizer-BioNTech and Moderna combined projected to generate revenues of over $\$ 7$ obn. ${ }^{11}$ Governing a global pandemic vaccine market in the broader public interest requires governments to invest early and jointly in risky health technologies, according to shared rules.

Experts have called for the creation of an international fund of $\$ 15 \mathrm{bn}$ a year for pandemic preparedness to pay for vaccine research, development, and production (among other priorities), with countries contributing based on national income. ${ }^{3}$ The Coalition for Epidemic Preparedness Innovations (CEPI), a multilateral initiative and partner in Covax, has provided proof of principle for such a fund. It mobilised $\$ 1.4 \mathrm{bn}$ from governments to invest together, at risk and at scale, becoming the world's third largest source of public funding for covid-19 vaccine research and development.

CEPI made its first covid-19 grants in early 2020, showing that preparedness can pay off in rapid reaction times. Its investments in vaccine candidates and manufacturing are the most geographically diverse of any public funder, mitigating the risk of scientific failure and disruptions in supply. ${ }^{12}$ But CEPI also had to fundraise and compete with other research funders such as the US and German governments, which could rapidly mobilise more money and offer companies fewer access obligations. Ultimately, CEPI was unable to secure the access provisions needed to ensure an equitable global supply of vaccines. ${ }^{13}$

An adequately resourced international fund with strong conditions attached could address several of these challenges. However, such an ideal may lie beyond the reach of geopolitics today. The US, Europe, China, and Russia have competed more than collaborated in the development and deployment of covid-19 vaccines. ${ }^{14}$ Creation of regional funds or clubs of like-minded countries may be more feasible than a single, overarching global solution, as countries can invest in developers and producers closer to home. Successful procurement of covid-19 vaccines by the European Union and African Union highlight the feasibility of regional solidarity. Already, the EU is establishing a bloc-wide agency 
to develop pandemic health technologies, ${ }^{15}$ and a regional vaccine technology transfer hub is being created in South Africa. ${ }^{16}$

To ensure that such initiatives add up to a coherent global system, however, they must commit to common rules on technology sharing that allow all regions to produce any successful vaccines. Such rules must be negotiated to serve the self-interests of all countries-a difficult task in this geopolitical climate, but well worth the effort to achieve greater health security with equity.

Competing interests: We have read and understood BMJ policy on declaration of interests and declare the following interests: SM is a member of the WHO Access to Covid-19 Tools Accelerator (ACT-A) ethics and governance working group, a non-remunerated position; AAR has been employed by IQVIA Spain, a data science company, for unrelated work.

Provenance and peer review: Commissioned; not externally peer reviewed.

1 Agarwal R, Gopinath G. A proposal to end the covid-19 pandemic. 2020 https://www.imf.org/en/Publications/Staff-Discussion-Notes/Issues/2021/05/19/A-Proposal-toEnd-the-COVID-19-Pandemic-460263

2 Independent Panel for Pandemic Preparedness and Response. Covid-19: make it the last pandemic 2021. https://theindependentpanel.org/wp-content/uploads/2021/05/COVID-19-Make-it-theLast-Pandemic_final.pdf

3 G20 High-Level Independent Panel. A global deal for our pandemic age. 2021. https://www.g20.org/wp-content/uploads/2021/07/G20-HLIP-Report.pdf

4 WHO Director-General's opening remarks at 148th session of the executive board. 2021. https://www.who.int/director-general/speeches/detail/who-director-general-s-opening-remarksat-148th-session-of-the-executive-board

5 Mathieu E, Ritchie H, Ortiz-Ospina E, etal. A global database of COVID-19 vaccinations. Nat Hum Behav 2021;5:947-53. doi: 10.1038/s41562-021-01122-8 pmid: 33972767

6 Global Health Centre. Covid-19 vaccine purchases and manufacturing agreements. 7 Sep 2021 https://www.knowledgeportalia.org/covid19-vaccine-arrangements

7 Global Health Centre. Covid-19 vaccine R\&D funding. 8 Jul 2021. https://www.knowledgeportalia.org/covid19-r-d-funding

8 Kiszewski AE, Cleary EG, Jackson MJ, Ledley FD. NIH funding for vaccine readiness before the COVID-19 pandemic. Vaccine 2021;39:2458-66.

doi: 10.1016/j.vaccine.2021.03.022 pmid: 33781600

9 GAVI. The covid-19 vaccine race-weekly update. 15 Sep 2021. https://www.gavi.org/vaccineswork/covid-19-vaccine-race

10 Paton JA. \$190 billion covid vaccine bonanza. Bloomberg 2021 May 29; https://www.bloomberg.com/news/newsletters/2021-05-29/a-190-billion-covid-vaccine-bonanza

11 Kansteiner F. BioNTech, eyeing \$18B-plus in covid-19 vaccine sales this year, poised to join the ranks of the world's top drugmakers. Fiercepharma.com. 2021. https://www.fiercepharma.com/pharma/pfizer-partner-biontech-eyeing-18-7b-covid-19-vaccine-sales-year-could-joinranks-world-s

12 Moon S, Alonso Ruiz A, Vieira M. Averting future vaccine injustice. N Engl J Med2021;385:193-6. doi: 10.1056/NEJMp2107528 pmid: 34265190

13 Usher AD. CEPI criticised for lack of transparency. Lancet 2021;397:265-6. doi: 10.1016/S0140-6736(21)00143-4 pmid: 33485436

14 Moon S, Kickbusch I. A pandemic treaty for a fragmented global polity. Lancet Public Health 2021;6:e355-6. doi: 10.1016/S2468-2667(21)00103-1 pmid: 33964229

15 Nakweya G. Africa 'tech hub' aims to fill COVID-19 vaccine gap. 2021. https://www.gavi.org/vaccineswork/africa-tech-hub-aims-fill-covid-19-vaccine-gap

16 European Commission. European Health Emergency Preparedness and Response Authority: about this initiative. 2021. https://ec.europa.eu/info/law/better-regulation/have-your-say/initiatives/12870-European-Health-Emergency-Preparedness-and-Response-Authority-HERA-_en

This article is made freely available for use in accordance with BMJ's website terms and conditions for the duration of the covid-19 pandemic or until otherwise determined by BMJ. You may use, download and print the article for any lawful, non-commercial purpose (including text and data mining) provided that all copyright notices and trade marks are retained. 